\title{
A Managerial Research of Online Education in the Primary and Secondary Romanian Education System During COVID 19 Crisis
}

\author{
Eduard Edelhauser ${ }^{1, *}$, and Lucian Lupu-Dima ${ }^{2}$ \\ ${ }^{1}$ Head of the Management and Industrial Engineering Department, University of Petroșani, Petroșani, \\ 332006 Romania \\ ${ }^{2}$ Mining Engineering, Surveying and Construction Department, University of Petroșani, Petroșani, \\ 332006, Romania
}

\begin{abstract}
The authors tried to analyse the implication of one year of online education in the Romanian primary education, lower secondary education, upper secondary education and even in the early childhood system. COVID-19 was seen as a social phenomenon world-wide and also in Romanian, that affected many elements of the society, including education. The study is based on a survey and used the online questionnaire investigation composed of 10 questions and authors have received more than 2500 answers from the respondents. The investigation took place during 29th of January 2021 and 11th of February 2021. The study concluded that, in the Romanian primary and secondary education system most schools migrated quickly to an online education system. The result shows also that over $82 \%$ of the students have participated rhythmic to online education and $50 \%$ to $60 \%$ of them used a Google Classroom platform or another virtual classroom. In the authors opinion the future of the Romanian education system will represent from now on a continuous debate between classic and online education, considering that only $10 \%$ of the Romanian students have no access to Internet and another $8 \%$ of the students did not have a computer, a laptop, a tablet, or a smartphone and obvious could not take online classes.
\end{abstract}

\section{Introduction}

In the school year 2020-2021, taking into account the epidemiological situation of each locality in Romania, the Romanian authorities announced for the new school year different learning models. Three scenarios were designed, face to face called green, online called red and hybrid. At the beginning of the 2020-2021 school year, most schools started in the green scenario. But despite this prognosis the scholastic year used in the first six months was in most cases the red scenario equivalent with the online learning method. The Romanian Education System include 2,800,000 students and over 200,000 teachers in the primary and secondary education levels. The Ministry of Education reports are made

* Corresponding author: eduardedelhauser@upet.ro 
through the eight development regions, the coloured one from the table presented in the methodology part, even if the School Inspectorate are organized through 41 counties.

Based on the authors experience [1,2] in the field of education, but also their work in the ICT field, with an experience of more than 25 years and more the 100 papers published in the information system and eLearning domain [3], they have decided to make an investigation over the online experience in the Romanian Education System after one year of pandemic. The paper based on questionnaires surveys investigated in fact the main features of a standard online or classical eLearning solution, such as the meeting solution or the videoconference software, the collaborative work such as homework or projects and the testing method or the quizzes, used in Romanian education system during COVID-19 pandemic.

\section{Theoretical Framework}

\subsection{Online education during COVID-19 pandemic}

The COVID-19 pandemic has changed education forever. The COVID-19 has resulted in schools shut all across the world. Globally, over 1.2 billion children are out of the classroom. As a result, education has changed dramatically, with the distinctive rise of elearning, whereby teaching is undertaken remotely and on digital platforms. Research suggests that online learning has been shown to increase retention of information, and take less time, meaning the changes coronavirus have caused might be here to stay [4-7]. While countries are at different points in their COVID-19 infection rates, worldwide there are currently more than 1.2 billion children in 186 countries affected by school closures due to the pandemic. With this sudden shift away from the classroom in many parts of the globe, some are wondering whether the adoption of online learning will continue to persist postpandemic, and how such a shift would impact the worldwide education market.

As schools around the world respond to COVID-19, the need for remote learning tools has never been more urgent. To make the transition to distance learning easier, different software companies have created resources, training and "how-to guides" that could help schools, educators, students, and their families as they navigate their "new normal."

\subsection{An overview over the worldwide meeting solutions market}

The pandemic caused by COVID-19 also affected the way students and teachers communicate. The entry of humanity into the digital age has proved favourable in this context for online communication and online education. The large number of video conferencing opportunities has been beneficial. The possibility to choose, offers users advantages, but also disadvantages. This makes it necessary to analyse different video conferencing platforms. A comparison between the current most popular Cloud-based online video conferencing tools: Zoom, Microsoft Teams and Google Meet is very important, because this meeting solutions were mostly selected by the Romanian teachers for online teaching during the COVID-19 pandemic. The authors have analysed the functionalities and the limitations to see which one suits better for online education (Fig. 1).

Google Meet Zoom and Teams have similar features and tools. This makes video conferencing work for business or education. These tools are very useful for those who work from the office or even from home. Google Meet and Microsoft Teams are suitable for people who want to collaborate in real time. This suitability is supported by the integration with Google Workspace, formerly G Suite and Office 365 - office suites that several companies already have available for employees. 


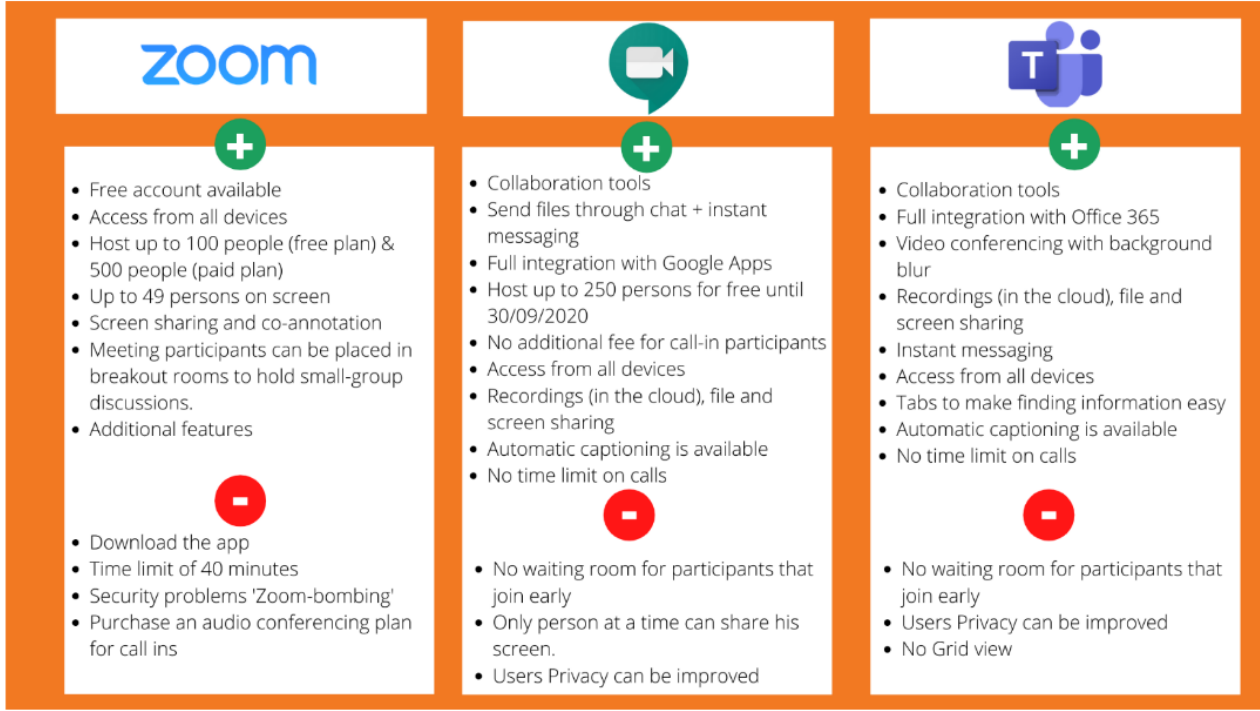

Fig. 1. Overview of online video conferencing tools by comparison [8].

Google Meet stands out as a better option for video calling by meeting because Meet doesn't charge an additional call fee. Undoubtedly, it cannot be said that one of the video conferencing tools is the best. Finally, users choose the video conferencing tool according to their own needs and the context of their activity [9].

\subsection{Learning platforms used in Romania in 2020 during the COVID-19 pandemic}

One year ago, the authors of this paper have made a survey in April 2020 over the online education at the University of Petroșani [11]. The important conclusion of this short research is that probably the education in Romania will never look the same after the COVID-19 pandemic, the classic education will probably suffer important changes due to these three months of exclusive online education in the whole system (Fig. 2). Certainly, ICT will influence education more than it has done so far, future curricula will need to contain e-learning tools, classes will be increasingly virtual, and online testing will become commonplace.

Also, a research team of 10 professor of the University of Bucharest have made a study over the primary and secondary Romanian education system with a number of 6,000 respondents [12]. The authors of this study noted at that time that teachers and students use several means to carry out learning activities that needed to be conducted online. These include: Simple/already known applications for asynchronous group communication, such as Facebook Messenger or WhatsApp: 91\% - average of 3.66 on a scale of 1-4; Telephone calls/SMS/communication channel with each student: $83 \%$ - average of 3.34; Use of digital content or open resources, such as information and illustration sites, virtual labs, online libraries, educational software, virtual museums, Learning Apps, Digitaliada: average of 2.82; Specialized eLearning platforms - Moodle, Google classroom, Edmodo, Easyclass: 2.6; Applications for synchronous group communication via video calls/video conferencing such as Webex, Google Meet, Zoom, Microsoft Teams, Skype: 2.48. 


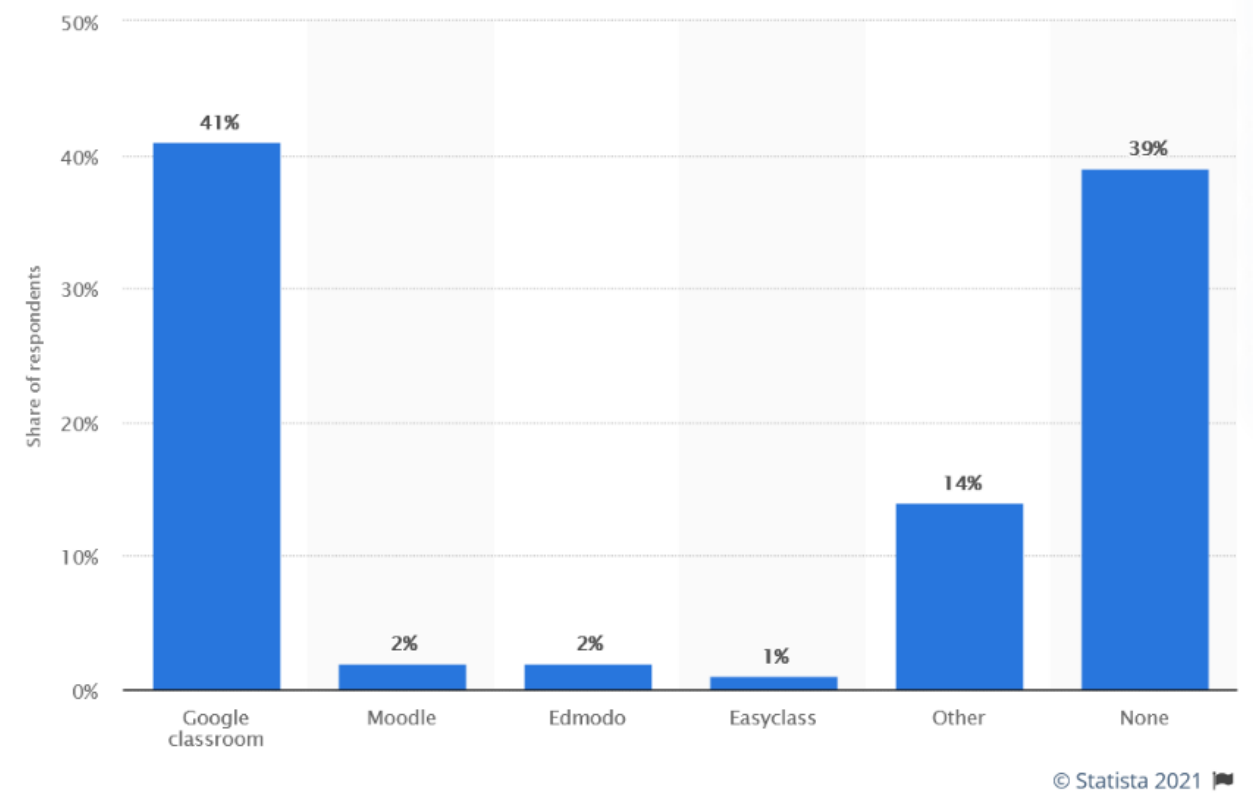

Fig. 2. Analysis of the use of online learning platforms in Romania 2020 during the COVID-19 epidemic [10].

Also, they conclude that, $37 \%$ of the teachers consider themselves advanced users of new technologies, but not necessarily advanced users of educational platforms, and $53 \%$ consider themselves intermediate users. Combined, the two percentages, 90\%, represent a more than satisfactory answer, even significant, regarding the level of self-perceived performance in the use of ICT, and can be a consistent starting point in carrying out further activities of continuous training for the development of digital skills, required in teaching, with a focus on virtual classroom, online learning platforms, applications and virtual labs [12].

The same results were obtained by the authors of this paper at that moment in the University of Petroșani online education, but in the academic field [11].

\section{Methodology}

\subsection{Population and Sample}

The authors began the study by contacting the forty-one county school inspectorates (CISISJ) to ask for help in applying the questionnaires. Even though the survey was applied online and has only 10 questions, in order to contact the teachers from the structure of Romanian primary and secondary education system (RPSES), the authors needed the help of the CIS. As a result of the support received, the authors reach a large number of respondents. The total number of respondents, teachers at ISCED level from 0 to 3 of education in the Romanian education system was 2,540 . This number represents $2 \%$ of the total number of teachers in the 6 selected regions of Romania $(153,647)$.

Of the 41 counties, the authors received answers from 18 counties, which could be grouped in 6 out of total 8 development regions from Romania, mentioned in table 1 . The 
number of respondents, compared to the total number of teachers in the Romanian development region, represents $0.3 \%$ to $3.2 \%$ of the total.

Table 1. Number of respondent teachers assigned to their county and region.

\begin{tabular}{|c|c|c|c|c|c|}
\hline Region & County & Number & Region & County & Number \\
\hline \multirow[t]{4}{*}{ North - West } & Maramures & 44 & Bucuresti - Ilfov & Bucuresti & 340 \\
\hline & Bistrita-Nasaud & 41 & & Total & 340 \\
\hline & Cluj & 37 & South - Muntenia & Calarasi & 100 \\
\hline & Total & 122 & & Giurgiu & 142 \\
\hline \multirow[t]{5}{*}{ Center } & Harghita & 343 & & Teleorman & 137 \\
\hline & Alba & 120 & & Total & 379 \\
\hline & Brasov & 79 & South - East & Buzau & 340 \\
\hline & Sibiu & 127 & & Braila & 203 \\
\hline & Total & 669 & & Tulcea & 114 \\
\hline \multirow[t]{4}{*}{ West } & Hunedoara & 127 & & Constanta & 107 \\
\hline & Arad & 65 & & Total & 764 \\
\hline & Other county & 52 & & & \\
\hline & Total & 244 & & & \\
\hline
\end{tabular}

Based on the $2 \%$ respondents out of the total number of teachers and also based on the county school inspectorates support for selecting the respondents, it can be considered that sample is representative and also only a few studies have been made in the RPSES whit such a great number of respondents.

\subsection{Instruments \& Investigation Tools}

The study conducted by the authors was based on a questionnaire survey conducted online, consisting of 10 questions. Of these, 5 are dedicated to the online education methods used and 3 are dedicated to the impact on students, and respondents responded in a standard of 4 minutes per interview. The investigation took place between January 29, 2021 and February 11, 2021.

\section{Results}

\subsection{Data description and graphical results}

The authors of the investigation made for the Romanian primary and secondary education system (RPSES) have used five questions dedicated to the online education methods used by teachers during the pandemic. Were analysed mainly the meeting solution or the 
videoconference software, the collaborative work such as homework or projects and the testing method or the quizzes (Fig. 3).

\section{Teaching method}

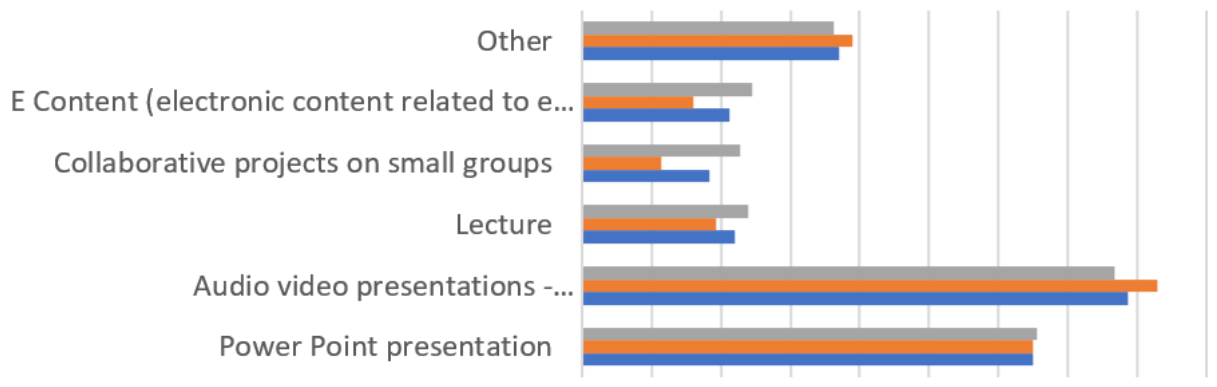

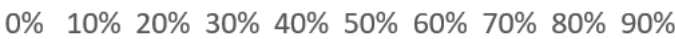

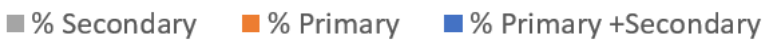

Fig. 3. Teaching method used during the COVID 19 pandemic (Q8).

In terms of teaching methods, it is found that PowerPoint presentations or video meetings are preferred by over $66 \%$. However, the method of sending pdf files by email probably exceeds $40 \%$.

\section{Video conferencing application}

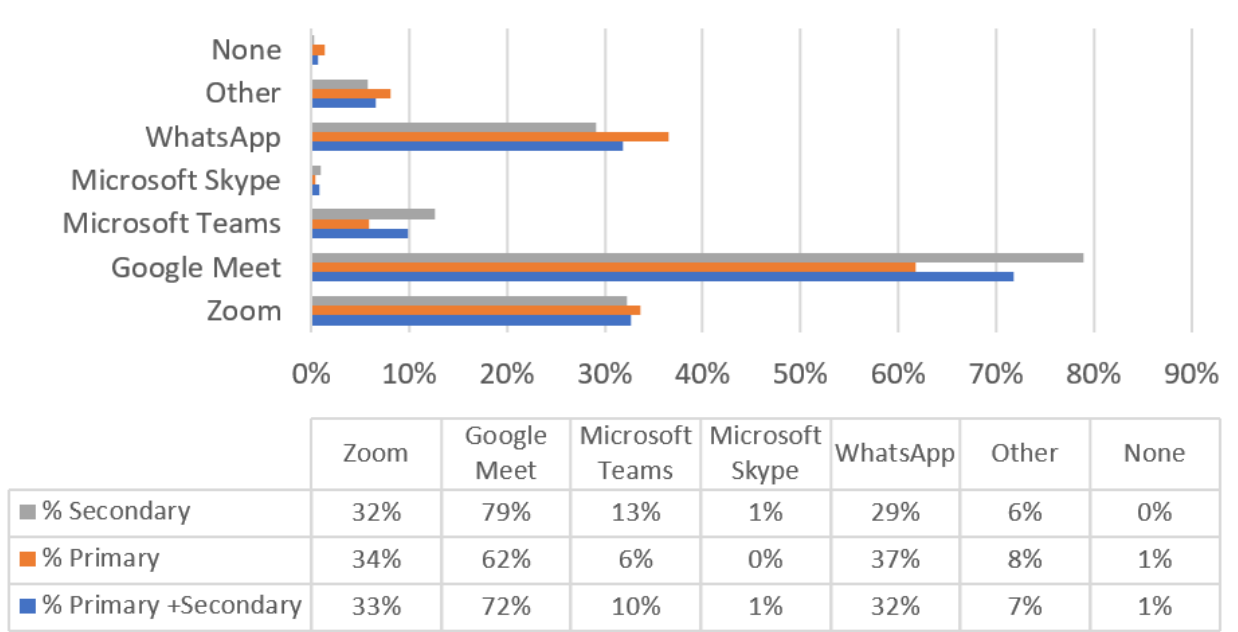

Fig. 4. Video conferencing software used for teaching during the COVID-19 pandemic (Q6).

An interesting observation that shows the differences between teachers working at different levels in education is related to the methods used for online meetings. Primary school teachers used WhatsApp more for meetings, while secondary school teachers chose to use less sophisticated methods for meetings, such as Microsoft and Google solutions (Fig. 4). 


\section{Collaborative platform or Virtual classroom}

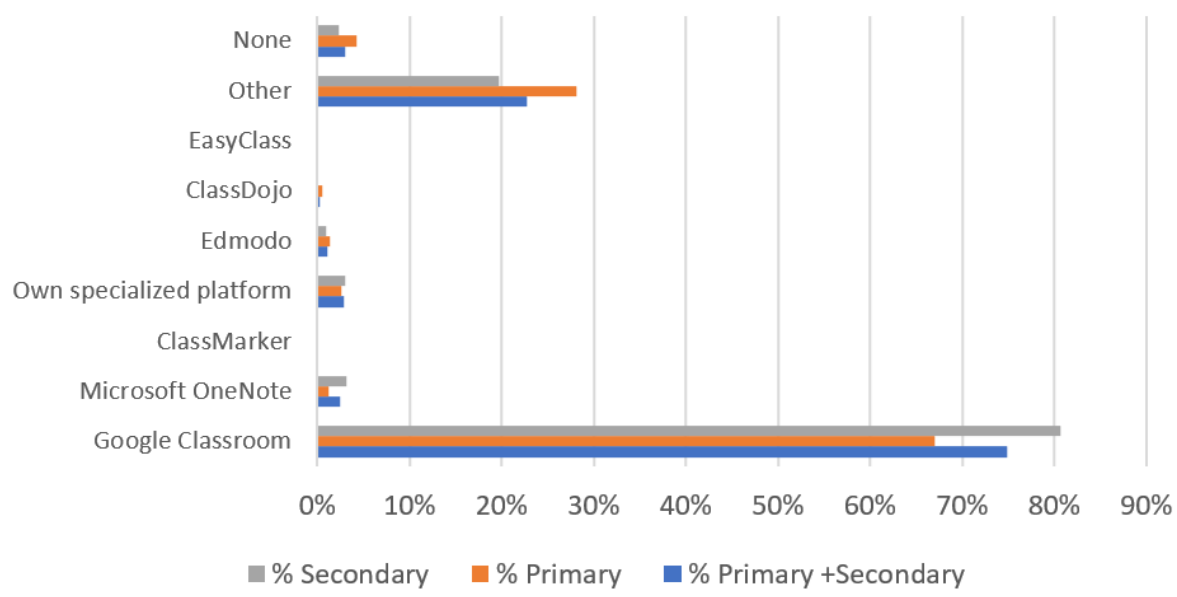

Fig. 5. Collaborative platform or virtual classroom used for student management, transmission of materials, homework, or progress during the COVID 19 pandemic (Q7).

Looking at which collaboration platforms were used in RPSES, it is found that Google G Suite for Education is 20 times more used than Microsoft Office 365 Academic or any other collaboration platform (Fig. 5).

\section{Testing or examination method}

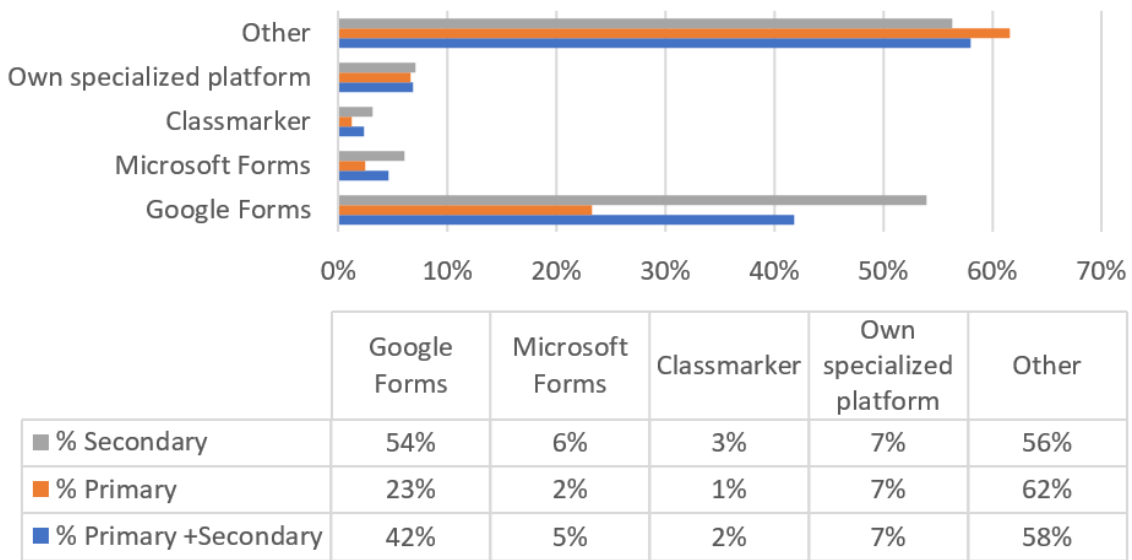

Fig. 6. Testing or examination method used during the COVID 19 pandemic (Q9).

In the online system, so in online courses, the testing method has an important role, just like the online meeting. The use of Quizzes found on specialized collaboration platforms such as Google, Microsoft or Class Marker is very different from classic testing. The difference is due to the imposition of a clear time limit, which creates additional pressure. Other elements that make the difference are the objective testing method or the impersonal feature of a digital platform. These problems may have led primary and secondary school teachers to prefer other testing methods, such as homework or video meetings (Fig. 6). 


\section{Homework transmission method}

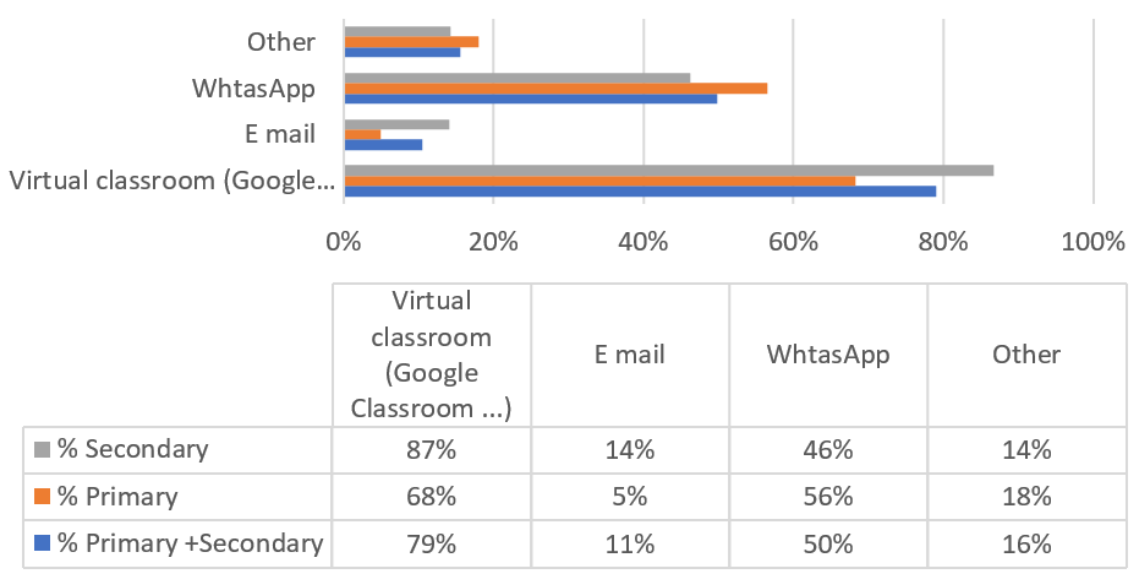

Fig. 7. Homework transmission method used during the COVID 19 pandemic (Q10).

Regarding the method of transmitting homework, the WhatsApp platform is widely used in RPSES. As the vast majority of schools and high schools have implemented the use of institutional e-mail addresses for students, connected to specialized platforms, especially Google Classrooms, the virtual classroom has become widely used for homework submission (Fig. 7).

\subsection{A comparative analysis of the perception of online education in Romanian academic and primary and secondary education}

The authors' preoccupation with this field led them to make another investigation on the Romanian academic education system using their own university, the University of Petroșani, as a case study.

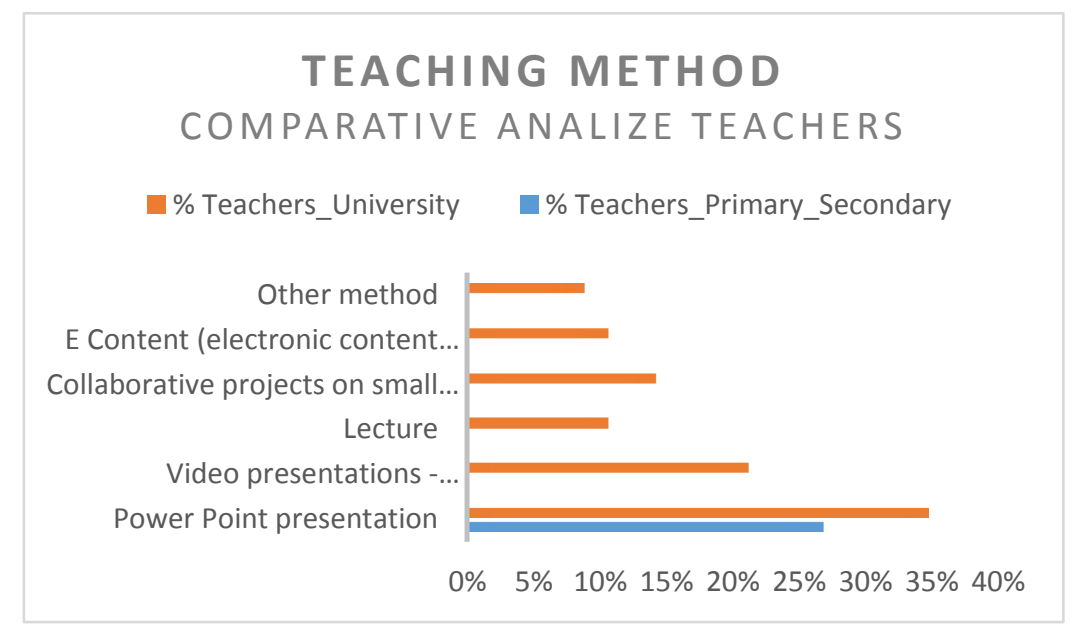

Fig. 8. Different perception for teaching method used by academic teachers and primary and secondary teachers. 
The investigation applied to the professors of the University of Petroşani was based also on an online questionnaire, a questionnaire composed of 12 questions. These questions were divided into two parts, 6 dedicated to the online education methods used and 6 the impact on students. In this investigation the authors receive 80 responses from 125 selected respondents, who responded within a standard time of 8 minutes per interview. The survey took place between January 29, 2021 and February 2, 2021.

The comparative analysis performed by the authors is called "Academic Teachers point of view versus Primary and Secondary Teachers point of view". Considering the different topics from the academic stage and at primary and secondary level, there are small differences. It becomes obvious that video presentations were preferred by pupils, while e Content and collaborative projects are preferred by students (Fig. 8).

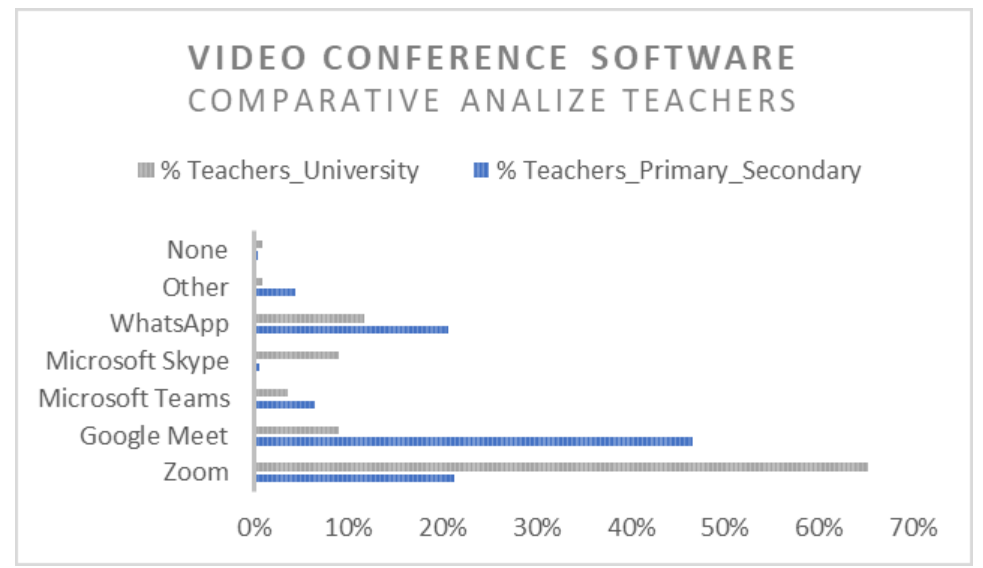

Fig. 9. Different perception for video meeting method used by academic teachers and primary and secondary teachers.

As was normal to be the meeting solutions were widely used at the academic and primary and secondary levels. The only difference noticed was that in the University of Petroșani the vast majority of teachers chose the Zoom solution, while in the primary and secondary education system Google Meet was selected (Fig. 9). It is also relevant that WhatsApp remains an option only for the level of primary education.

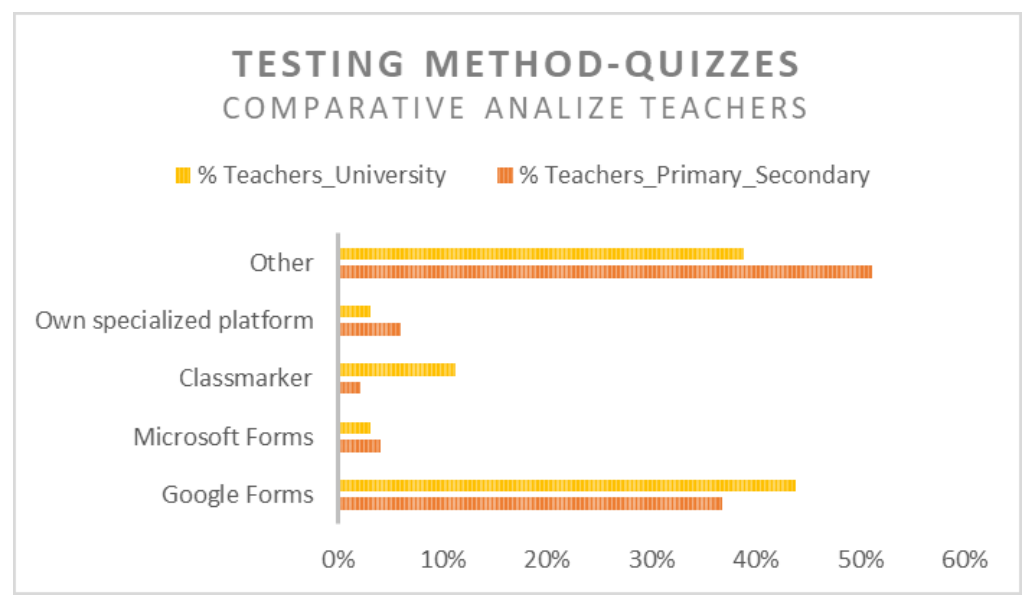

Fig. 10. Different perception for testing method used by academic teachers and primary and secondary teachers. 
Teachers in higher education, as well as teachers in primary and secondary education, chose Quizzes for testing, using forms from Google, Microsoft, Class Marker or their own test module developed, the differences being quite small between the two categories of teachers (Fig. 10).

Regarding the method of transmitting homework used by pupils and students, the only relevant difference is that, although e-mail is an academic solution, WhatsApp can be considered a solution for the primary education system (Fig. 11).

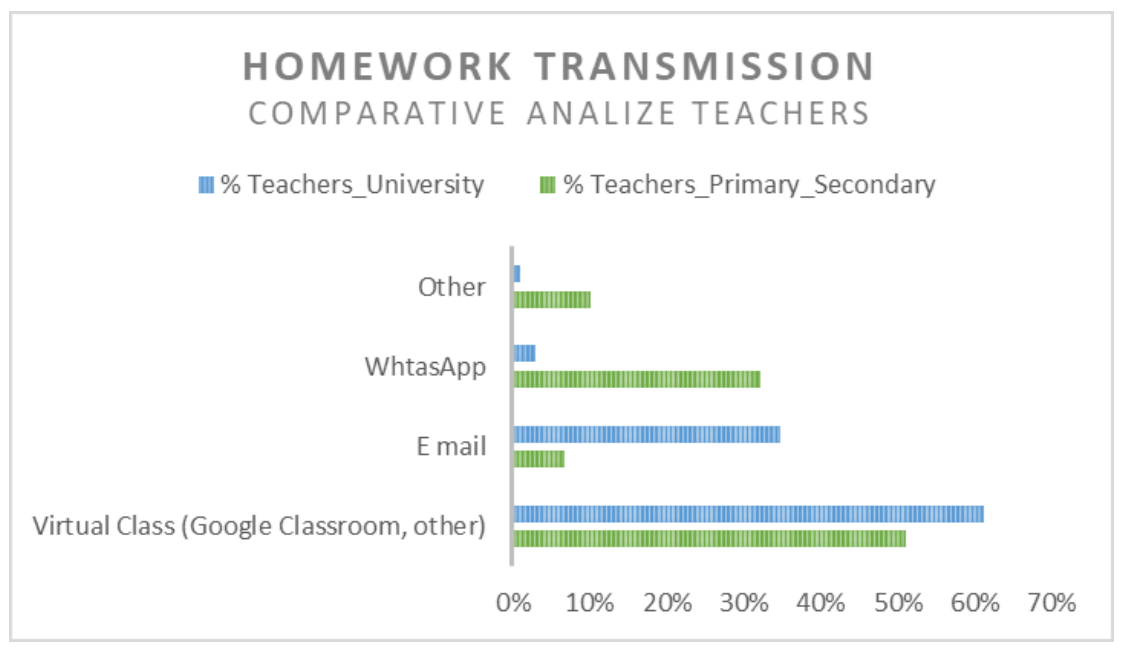

Fig. 11. Different perception for homework transmission method used by academic teachers and primary and secondary teachers.

\subsection{Statistical analysis}

The authors validated the hypothesis that there is a strong relationship between the online teaching effort in two different levels of education, such as academic and primary and secondary, using statistical analysis applied on the surveys conducted in January - February 2021. In order to identify the effect that the implementation of online education in the Romanian education system will have on students, the authors performed a multiple regression analysis. The authors used regression analysis and correlation analysis for the intensity of connections between variables. In this way the authors estimated the value of a dependent variable (effect). To obtain a result with maximum validity, the authors used the values of other independent variables (causes).

Table 2. Regression analysis of and correlation between the perspective of primary and secondary education level teachers and academic teachers over teaching methods.

\begin{tabular}{|c|c|c|c|c|c|c|}
\hline \multicolumn{5}{|c|}{ Model Summary } & & \\
\hline Model & $\mathrm{R}$ & R Square & $\begin{array}{l}\text { Adjusted } \\
\text { R Square }\end{array}$ & $\begin{array}{l}\text { Std. Error of } \\
\text { the Estimate }\end{array}$ & & \\
\hline 1 & $0,872^{\mathrm{a}}$ & 0,760 & 0,712 & 13,325 & & \\
\hline \multicolumn{7}{|c|}{ a. Predictors: (Constant), Teachers_Primary_Secondary } \\
\hline \multicolumn{7}{|c|}{ ANOVA $^{a}$} \\
\hline & & $\begin{array}{l}\text { Sum of } \\
\text { Squares }\end{array}$ & $\mathrm{df}$ & $\begin{array}{l}\text { Mean } \\
\text { Square }\end{array}$ & $\mathrm{F}$ & Sig. \\
\hline
\end{tabular}




\begin{tabular}{|c|c|c|c|c|c|c|}
\hline \multirow{3}{*}{1} & Regression & $\begin{array}{c}2809,70 \\
1\end{array}$ & 1 & 2809,701 & 15,825 & $0,011^{\mathrm{b}}$ \\
\cline { 2 - 7 } & Residual & 887,727 & 5 & 177,545 & & \\
\cline { 2 - 7 } & Total & $\begin{array}{c}3697,42 \\
9\end{array}$ & 6 & & & \\
\hline \multicolumn{7}{|c|}{ a. Dependent Variable: Teachers_University } \\
\hline
\end{tabular}

Analysing the results obtained (Table 2), the authors noticed that there was a very strong link between the perspective of primary and secondary teachers and academic teachers towards online teaching methods (with a significance of the correlation $\mathrm{R}=0.872$ $>0.63$ for 5 degrees of freedom representing as PowerPoint presentation, video presentation, lecture, collaboration projects or e Content methods). Test $\mathrm{F}$ produces a value $(15,825)$ that is high. It is found that Sig. the corresponding F statistic is $0.011(0.00)$. According to these values, the two variables are in a significant linear relationship. Because both Fs are large and the significance of Sig. is low, it can be concluded that the results are not accidental. The value of the regression coefficient $\mathrm{R}=0.872$ shows a strong connection between the variable Nr. by professors of the University of Petroșani and the independent variable $\mathrm{Nr}$. of teachers in the primary and secondary education system. The model thus created explains $87 \%$ of the total variation of the variable $\left(\mathrm{R}^{2}=0.76\right)$. The remaining $23 \%$ is due to other residual factors that are not included in the model. It is found that the teaching methods proposed by teachers in the primary and secondary education system have been validated by the options of teachers at the University of Petroșani. So, the testing method used by primary and secondary teachers are applied in the same way by the professors of the University of Petroșani.

\section{Discussion and Conclusions}

The paper based on questionnaires surveys investigated in fact the main features of a standard online or classical eLearning solution, such as the meeting solution or the videoconference software, the collaborative work such as homework or projects and the testing method or the quizzes, used in Romanian education system during COVID-19 pandemic.

As teaching methods used in RPSES, the authors find that power point presentations and video meeting are preferred by more than $66 \%$ of the teachers. Also, more than $40 \%$ of the teachers have used only documents sent by email as a teaching method. It is found that primary school teachers have used WhatsApp more for meetings, while secondary school teachers use Microsoft and Google as meeting methods, but also as collaboration solutions. In RPSED Google Workspace is maybe 20 times more used than Microsoft Office 365.

In the second part of the paper through the benchmark analysis, authors have identified small differences, but it was relevant that video presentations were preferred by pupils while e Content and collaborative projects are preferred by students. In the meeting solutions field, these solutions were widely used bout in academic level and primary and secondary level, Zoom at the authors university (University of Petrosani), and Mett in the RPSES. The only relevant difference in the homework transmission method used by the students and pupils is that while email is an academic solution.

As a final conclusion we have to mention a result obtain after one year on online education experience in the Romanian education system, meaning that teachers have left behind the hybrid communication methods with the students, such as Facebook and 
WhatsApp, and have passed to the videoconference and collaborative platforms, even if WhatsApp can be considered a solution for the primary education system.

Another relevant conclusion that authors state at the end of these paper, is that future education will become more probably a hybrid one in the academic field, while in the secondary education online will probably remain only an adjuvant for the teachers. This conclusion is based on the fact that online represents for students the second nature, teacher are now, after one year of online education more prepared and trained and also the transition to distance learning is now easier because different software companies have created resources that could help both teachers and students to migrate more easily to the online system.

\section{References}

1. E., Edelhauser, R., Pleşa, L., Lupu, Supplement of Quality-Access to Success 18, S1, 408-413 (2017)

2. E., Jornea, L., Lupu-Dima, Eduard Edelhauser, 8th Int. Conf. MSE2017 - Trends in New Industrial Revolution, MATEC Web of Conferences 121, 07011 (2017)

3. E., Edelhauser, A., Ionică, Computer Science and Information Systems 11 (2), 809-823 (2014)

4. T., Chen, L., Peng, B., Jing, C., Wu, J., Yang, G., Cong, Sustainability 12, 7329 (2020)

5. D., Popa, A., Repanovici, D., Lupu, M., Norel, C., Coman, Sustainability 12, 8726 (2020)

6. C.A., Ionescu, L., Paschia, N.L., Gudanescu Nicolau, S.G., Stanescu, V.M., Neacsu Stancescu, M.D., Coman, M.C. Uzlau, Sustainability 12, 9030 (2020)

7. A., McNamara, Educ. Sci. 2021, 11(3), 132

8. C., Verbrugghe, Comparing Zoom, Microsoft Teams and Google Meet, https://gcloud.devoteam.com/blog/comparing-zoom-microsoft-teams-and-google-meet (Devoteam G Cloud, 2021)

9. G., Sevilla, Zoom vs. Microsoft Teams vs. Google Meet: Which Top Videoconferencing App Is Best? https://www.pcmag.com/news/zoom-vs-microsoft-teams-vs-google-meet-avideoconferencing-face-off (PCMag, 2020)

10. J. A., Sava, Most popular online learning platforms used during the coronavirus (COVID-19) pandemic in Romania in 2020, https://www.statista.com/statistics/1115202/romania-leadingonline-learning-platforms-during-covid-19/\#statisticContainer (2020)

11. E., Edelhauser, L., Lupu, Sustainability 12(13), 5438, (2020)

12. P., Botnariuc, et al., Scoala Online - Elemente Pentru Inovarea Educatiei, https://unibuc.ro/wpcontent/uploads/2020/05/Scoala_Online_Raport_aprilie_2020.pdf(Bucharest Univ. Pub., 2020) 